\title{
RANCANGAN APLIKASI PEMINJAMAN KENDARAAN OPERASIONAL PT. TELKOM AKSES STO KALIABANG
}

\author{
Aditya Pratama \\ Teknik Informatika, Fakultas Teknik dan Ilmu Komputer, Universitas Indraprasta PGRI Jakarta \\ Jalan Raya Tengah No 80, Kelurahan Gedong, Pasar Rebo, Jakarta Timur \\ pratamaaditya2598@gmail.com
}

\begin{abstract}
ABSTRAK
Permasalahan yang sedang terjadi pada PT. Telkom Akses STO Kaliabang adalah terjadinya kehilangan berkas pada saat pelaporan bulanan kepada pimpinan diakibatkan human error. Selain itu, Kendala yang timbul adalah pada saat proses pendataan dan sering terjadi kesalahan pencatatan dan pelaporan. Tujuan dari penelitian ini untuk merancang suatu sistem informasi peminjaman dan pengembalian mobil ini untuk memudahkan admin dalam memproses pengolahan data yang ada saat ini. Perangkat aplikasi yang telah dibuat dengan menggunakan bahasa pemrograman Java NetBeans 8.0.2 dan penyimpanan data yang disimpan didalam database MySQL dapat memberikan kemudahan dalam proses menginput dan menyimpan data-data serta laporan-laporan yang akan diberikan kepada Pimpinan perusahaan. Dengan memakai metode pengembangan sistem yaitu Waterfall dalam penelitian ini adalah dengan tahapan-tahapan seperti rekayasa sistem, analisis, desain, coding, testing, dan maintenance. Hasil dari penelitian ini menciptakan suatu sistem informasi peminjaman dan pengembalian mobil yang berisikan proses pendataan data karyawan, data peminjaman mobil karyawan serta proses pendataan data pengembalian mobil yang lebih baik dan akurat.
\end{abstract}

Kata Kunci: Sistem Informasi, Peminjaman, Kendaraan Operasional, Java

\section{ABSTRACT}

The problems found in PT. Telkom Akses STO Kaliabang are the occurrence of file loss during monthly reporting to the leadership due to human error. In addition, the obstacles that arise are during the data collection process and there are often recording and reporting errors. The purpose of this research is to design a loan and return information system for this car to facilitate admins in processing existing data. Application devices that have been created with the Java NetBeans 8.0.2 programming language and data storage in the MySQL database can provide smoothness in the process of inputting and storing data and reports given to company leaders. By using the system development method, namely Waterfall, in this research, the stages are systems engineering, analysis, design, coding, testing, and maintenance. The results of this study created a car loan and return information system that contains the process of collecting employee data, employee car loan data and a better and accurate car return data collection process.

Key Word: Information System, Borrow, Operational Vehicles, Java

\section{PENDAHULUAN}

Perkembangan teknologi informasi pada jaman seperti sekarang ini berkembang dengan pesat kemajuanya (Asra Mulya, Syarli, 2020). Kehadiran komputer ditengah-tengah aktivitas bagi kalangan bisnis, merupakan salah satu alternatif dalam mengatasi permasalahanpermasalahan yang makin sering terjadi dan untuk meningkatkan efektifitas serta efesiensi (Trenggono, 2014).

Pada saat ini sistem aplikasi sangat berpengaruh disegala bidang kehidupan baik dibidang politik, pendidikan, maupun ekonomi, khususnya dibidang peminjaman kendaraan operasional perusahaan. Tetapi dalam kenyataan masih banyak perusahaan yang masih menerapkan metode secara manual dan sistem manajemen dan administrasinya. Sehingga kesiapan untuk memenuhi kebutuhan karyawan belum maksimal dan menyulitkan karyawan dalam melakukan pengontrolan data dan pembuatan laporan kepada pimpinan. Untuk menghasilkan kualitas informasi yang lebih baik, serta secara akurat dalam memperbaiki kesalahan-kesalahan yang sedang terjadi dalam pekerjaan dengan sistem yang 
manual, maka perusahaan membutuhkan suatu sistem komputer yang dapat membantu kinerja karyawan serta mengefisiensikan berbagai sumber daya seperti waktu dan semua sumber daya (Shadiq, Safei, Wahyudin, \& Loly, 2021).

PT. Telkom Akses STO Kaliabang adalah sebuah perusahaan di bawah naungan PT. Telkom yang khusus bergerak dibidang marketing. PT. Telkom Akses STO Kaliabang yang beralamat di Jl. Raya Kaliabang Tengah No.1, RT.06/RW.04, Kel. Kaliabang Tengah, Kec. Bekasi Utara, Kota Bekasi, Jawa Barat 17125. Menurut pimpinan bagian operasional PT. Telkom Akses STO Kaliabang saat ini proses peminjaman dan pengembalian kendaraan operasional perusahaan dalam pencatatannya masih menggunakan cara manual dengan media kertas dan sering terjadi human error, pelaporan kepada pimpinan pun terkadang sering mengalami keterlambatan (Kurniawan \& Irsyadi , 2021).

Dengan permasalahan tersebut, perlu adanya suatu sistem yang terkomputerisasi dalam penyelesaiannya. Menurut Tata Sutabri(2012 : 3) menyatakan bahwa sistem dapat diartikan sebagai kumpulan dari unsur, kompenen, atau variabel yangterorganisasi, saling berinteraksi, saling tergantung satu sama lain. Menurut Tyoso (2016:1) menyatakan bahwa sistem adalah suatu kumpulan dari komponen-komponen yang membentuk satu kesatuan.. Pembangunan sistem adalah kumpulan aktivitas yang menggambarkan secara rinci bagaimana sistem akan berjalan. Hal ini bertujuan untuk menghasilkan produk perangkat lunak yang sesuai dengan kebutuhan user (Satzinger, J. W., Jackson, R. B., Burd, n.d.).

Diharapkan dengan adanya suatu sistem informasi dapat menangani permasalahan yang ada di perusahaan tersebut. Sistem adalah setiap sesuatu terdiri dari obyek-obyek, atau unsur-unsur, atau komponen-komponen yang bertata kaitan dan hubungan satu sama lain, sedemikian rupa sehingga unsur-unsur tersebut merupakan satu kesatuan pemrosesan atau pengolahan yang tertentu. (Prasojo, 2011)

Aplikasi ini dapat memudahkan pekerjaan Admin dalam melaksanakan pembuatan laporan dan dapat memudahkan perusahaan dalam pendataan data proses peminjaman kendaraan operasional yang lebih efektif (Pratama, Arifin, Citra, \& Dwi, 2020).

\section{METODE PENELITIAN}

Peneliti menggunakan metode Research and Development dalam penyelesaian penelitian ini(Sugiyono, 2016). Dalam penerapan R\&D, ada beberapa metode yang digunakan yaitu metode deskriptif, evaluatif dan eksperimental. Metode penelitian deskriptif digunakan dalam melakukan penelitian awal untuk menghimpun data tentang kondisi yang ada yaitu penulis membutuhkan data-data yang dapat menunjang terciptanya suatu sistem informasi peminjaman dan pengembalian mobil seperti data mobil, data karyawan, data petugas, data peminjaman mobil dan data pengembalian mobil terdahulu yang masih tersimpan secara manual di dalam buku besar.

Metode evaluatif digunakan untuk mengevaluasi proses ujicoba pengembangan suatu produk, dalam proses ini penulis melakukan ujicoba terhadap suatu sistem yang telah dirancang agar tidak ada terjadi kesalahan dalam proses penginputan data serta pelaporan bulanan kepada pimpinan. Dan metode eksperimen digunakan untuk menguji keampuhan dari produk yang dihasilkan, dalam proses yang terakhir ini perlu dilakukan pengujian akhir yang diharapkan bahwa sistem yang dirancang oleh penulis dapat berjalan dengan baik dan sesuai dengan kebutuhan dan terfokus pada proses peminjaman kendaraan operasional PT. Telkom Akses STO Kaliabang Bekasi.

\section{HASIL DAN PEMBAHASAN}

PT.Telkom Akses STO Kaliabang merupakan salah satu perusahaan yang belum memiliki sistem aplikasi pengolahan data dalam peminjaman kendaraan operasional berbasis kompeterisasi, ada beberapa masalah yang dirasakan perusaan yaitu masih melakukan pendataan secara manual sehingga menyusahkan karyawan dalam melakukan pencaraian data peminjaman dan seringnya terjadi kehilangan laporan data peminjaman. Pencatatan data peminjaman yang berjalan masih menggunakan kertas sebagai sarana pencatatan sebagai sarana peminjaman 
kendaraan operasional sehingga karyawan merasa kesulitan dalam mencari data.

Berdasarkan analisis sistem yang berjalan saat ini penulis melihat adanya kekurangan, maka penulis memberikan saran alternatif penyelesaian masalah dengan membuat sebuah aplikasi pengolahan data peminjaman kendaraan dengan menggunakan pemograman java dan menyimpan data pada media database MySQL..

Langkah pertama dengan menggunakan metode deskriptif yaitu dengan melakukan pengumpulan data data yang di perlukan untuk menunjang terciptanya suatu sistem informasi peminjaman dan pengembalian mobil dengan cara studi lapangan dan juga studi literatur. Langkah kedua dengan metode evaluatif yaitu penulis perlu melakukan evaluasi terhadap sistem yang telah di rancang dan melakukan uji coba terhadap sistem tersebut agar tidak terjadi kesalahan dalam melakukan proses input data serta pelaporan terhadap pimpinan. Langkah ketiga yaitu dengan metode eksperimen yaitu penulis melakukan pengujian terhadap sistem yang telah di hasilkan agar sistem yang telah di rancang dapat berjalan dengan baik dan sesuai dengan kebutuhan karyawan pada proses peminjaman kendaraan opersional pada PT. Telkom Akses STO Kaliabang Bekasi.

Setelah pengujian ternyata sistem yang di buat berjalan dengan baik dan sistem ini mampu membantu admin dalam melakukan proses penginputan data peminjaman kendaraan operasional dan memudahkan admin dalam melakukan laporan bulanan terhadap atasan. Dengan adanya sistem pencatatan secara komputerisasi ini admin dapat dengan mudah melakukan pencarian data peminjaman kendaraan operasional dan dapat lebih cepat dalam melakukan proses pembuatan laporan bulanan.

\section{Alternatif Penyelesaian Masalah}

Alternatif pemecahan masalah yang akan penulis lakukan untuk mempermudah proses kerja pada PT. Telkom Akses STO Kaliabang, yaitu:

1. Merancang sebuah sistem aplikasi yang lebih baik untuk dapat membantu kinerja bagian admin dalam mengelola setiap proses yang terjadi pada perusahaan serta membantu dalam mengolah data-data perusahaan.
2. Merancang sistem aplikasi manajemen data peminjaman dan pengembalian mobil dengan sistem terkomputerisasi. Jadi, setiap peminjaman dan pengembalian mobil yang terjadi, seperti proses peminjaman, pengembalian, dan data laporan akan disimpan ke dalam database. Kemudian laporan yang dibutuhkan akan dapat langsung ditampilkan secara otomatis tanpa harus menggunakan cara manual lagi. Dengan metode ini dapat memudahkan karyawan dalam melakukan pendataan dan dapat menghindarkan dari kehilangan berkas.

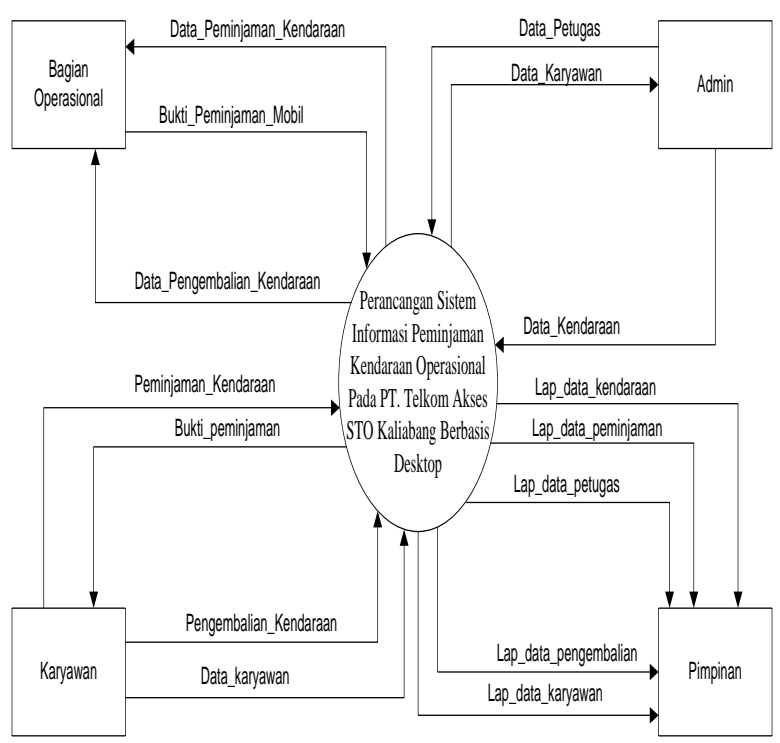

Gambar 1. Diagram Konteks

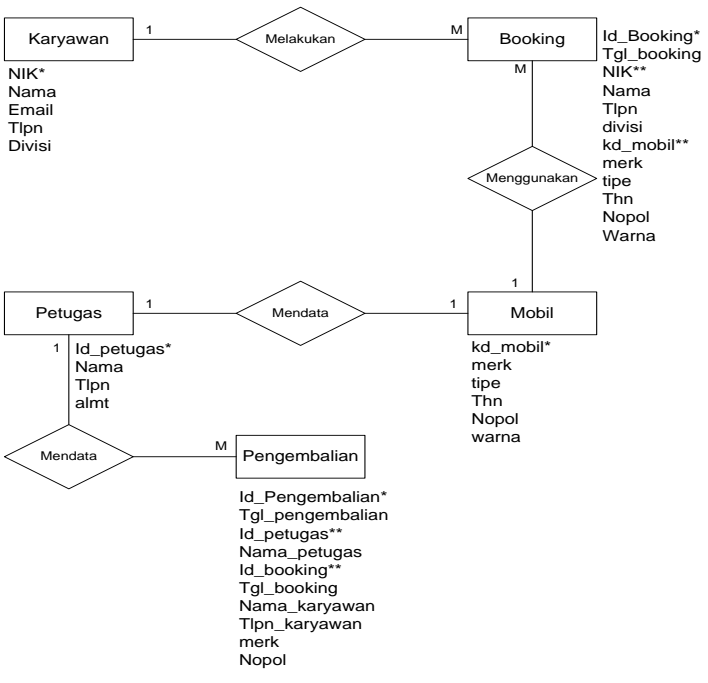

Gambar 2. ERD (Entity Relationship Diagram) 
Berikut merupakan tampilan layar dan hasil pengujian pada software program yang telah di buat dengan bahasa pemrograman Java.
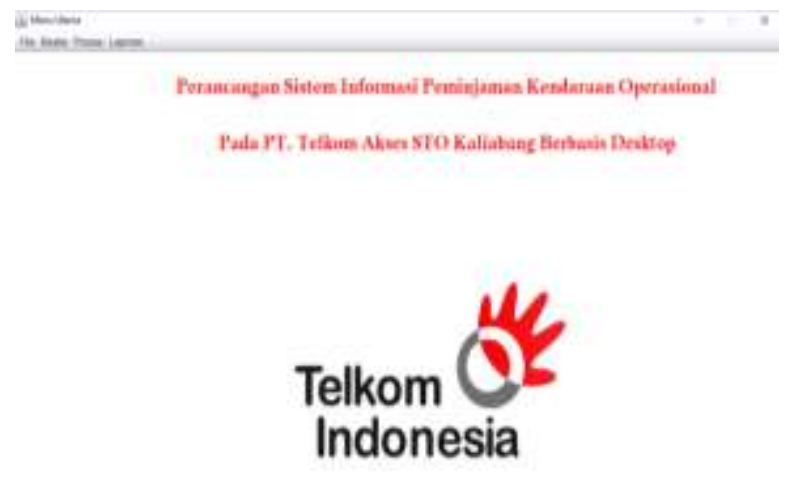

\section{Gambar 3. Form Menu Utama}

Layar di atas merupakan tampilan Menu Utama pada Aplikasi Peminjaman Kendaraan Operasional Pada PT. Telkom Akses STO Kaliabang. Pada layar utama terdapat menu bar yang terdiri dari master data yang digunakan untuk memasukkan data yang berkaitan dengan data karyawan, data petugas, data mobil, data peminjaman mobil, data pengembalian mobil dan laporan-laporan.

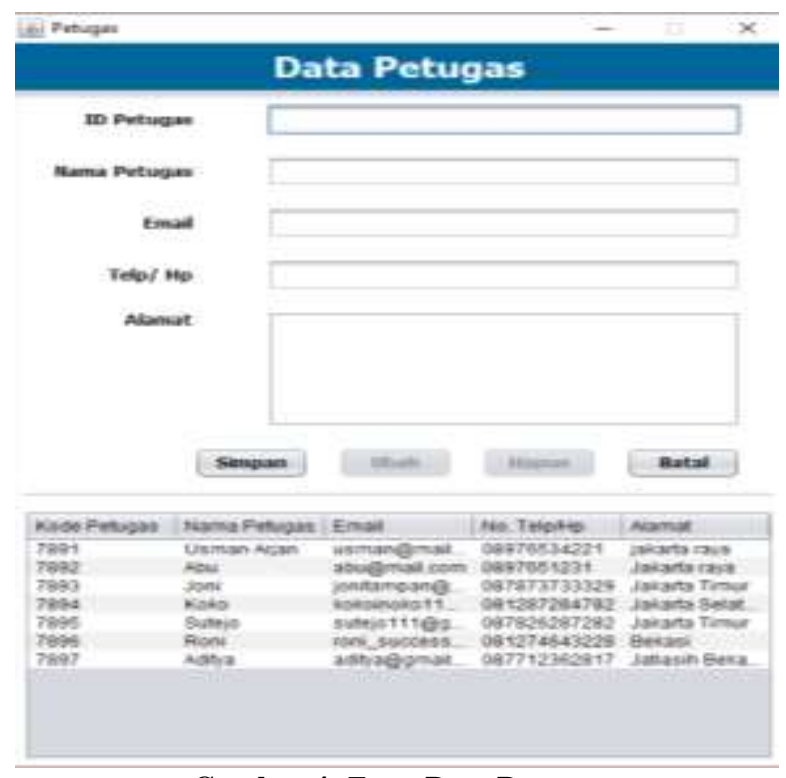

Gambar 4. Form Data Petugas

Layar di atas merupakan tampilan form data petugas. Pada layar form data petugas untuk meng-input data petugas yang terdiri dari Kode
Petugas, Nama Petugas, Email, No Telp dan Alamat.

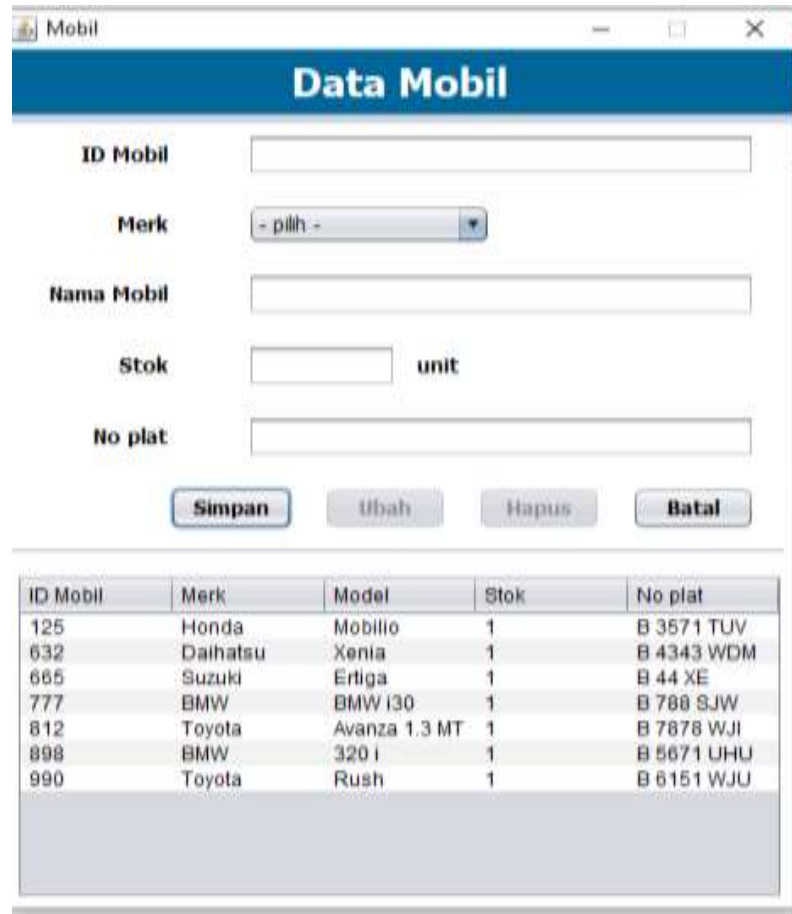

Gambar 5. Form Data Mobil

Layar di atas merupakan tampilan form data mobil. Pada layar form data mobil untuk menginput data mobil yang terdiri dari ID Mobil, Merk Mobil, Model, Stok dan No Plat Mobil.

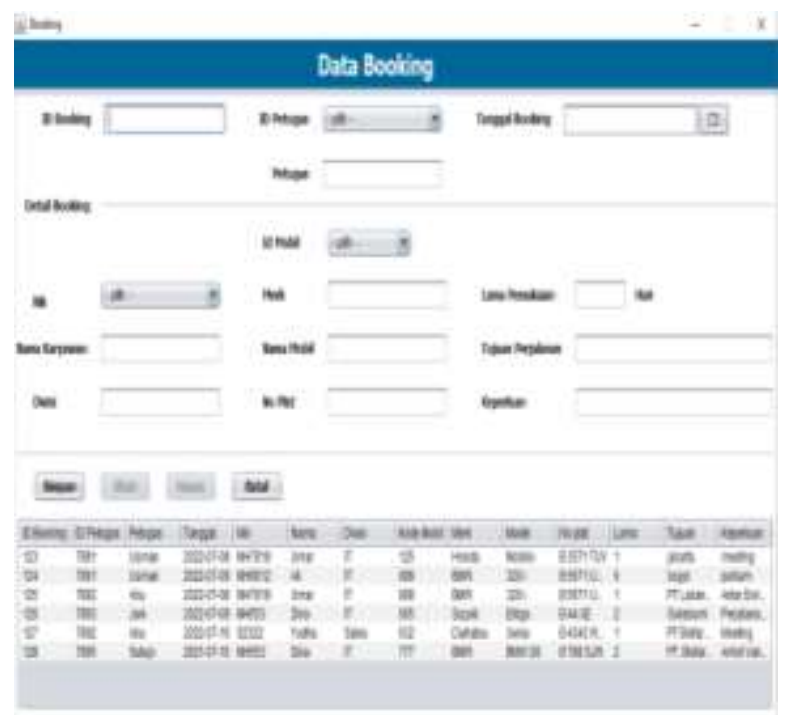

Gambar 6. Form Data Booking Mobil

Layar di atas merupakan tampilan form data booking mobil. Pada layar form data booking mobil digunakan untuk meng-input data booking 
mobil yang terdiri dari ID Booking, ID Petugas, Nama Petugas, Tanggal Booking, NIK, Nama Karyawan, Divisi, ID Mobil, Merk, Nama Mobil, No Plat, Lama Pemakaian, Tujuan Perjalanan dan Keperluan.

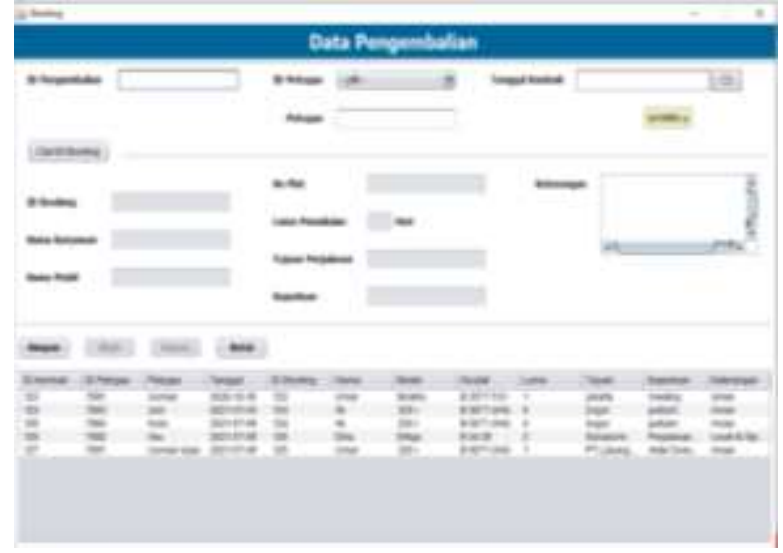

Gambar 7. Data Form Data Pengembalian Mobil

Layar di atas merupakan tampilan form data pengembalian mobil. Pada layar form data pengembalian mobil digunakan untuk meng-input data pengembalian mobil yang terdiri dari ID Pengembalian, ID Petugas, Nama Petugas, Tanggal Kembali, ID Booking, Nama Karyawan, Nama Mobil, No Plat, Lama Pemakaian, Tujuan Perjalanan, Keperluan dan Keterangan.

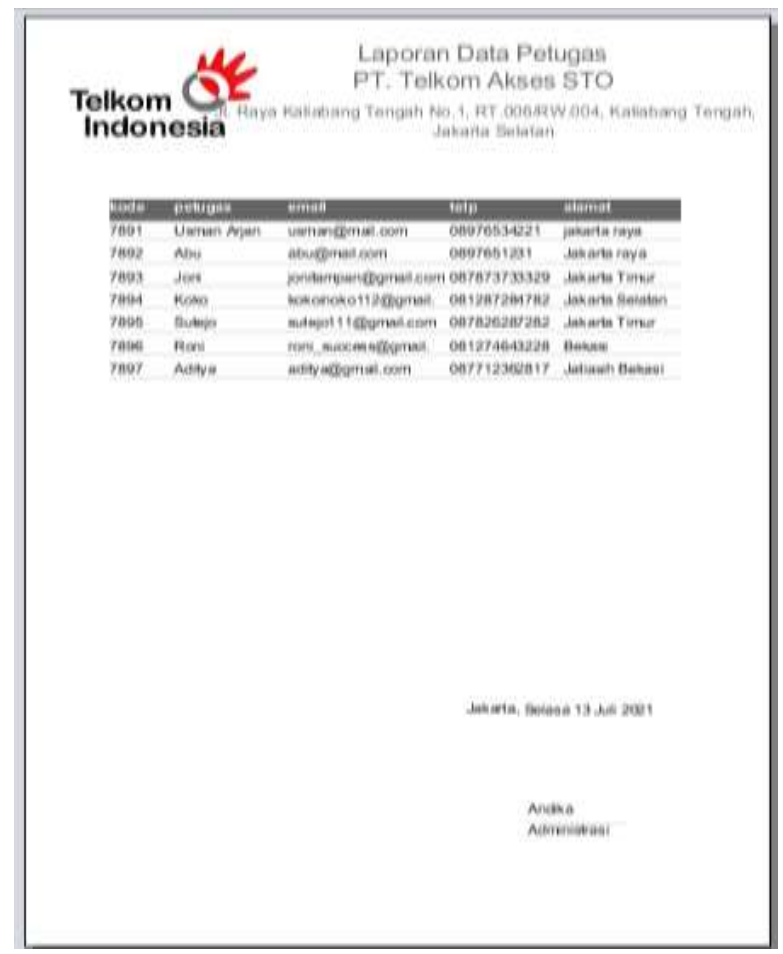

Gambar 8. Data Form Data Petugas
Layar di atas merupakan tampilan form data petugas. Pada layar form data petugas untuk meng-input data petugas yang terdiri dari Kode Petugas, Nama Petugas, Email, No Telp dan Alamat.

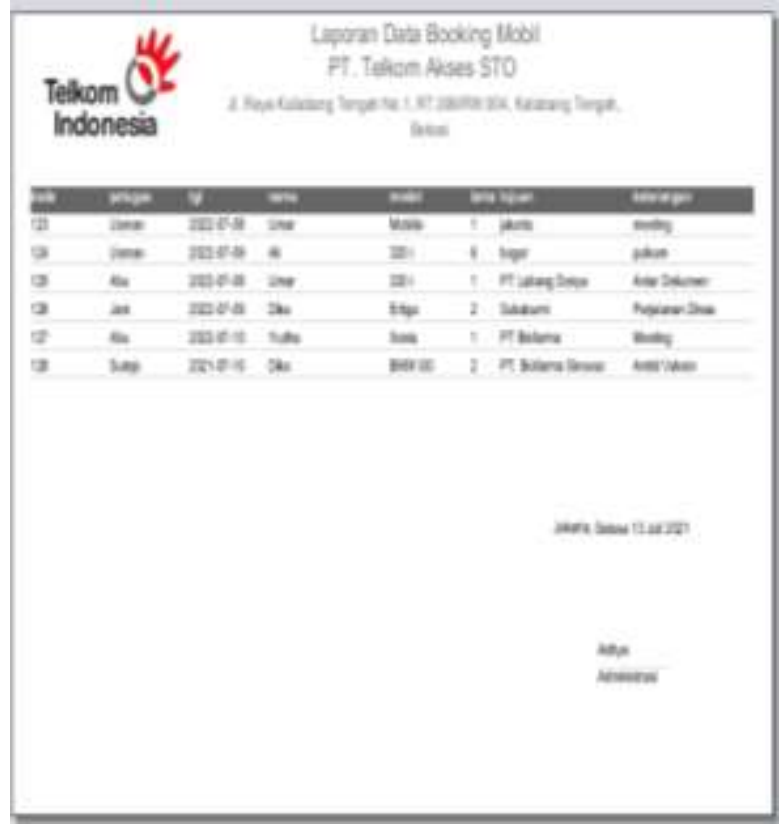

Gambar 9. Laporan Data Booking Mobil

Layar di atas merupakan tampilan dari form laporan data booking mobil. Pada layar form data absensi digunakan dalam melakukan pengecekan laporan data booking mobil yang terdiri dari Kode Booking, Nama Petugas, Tgl, Nama Petugas, Model, Lama Peminjaman, Tujuan dan Keterangan.

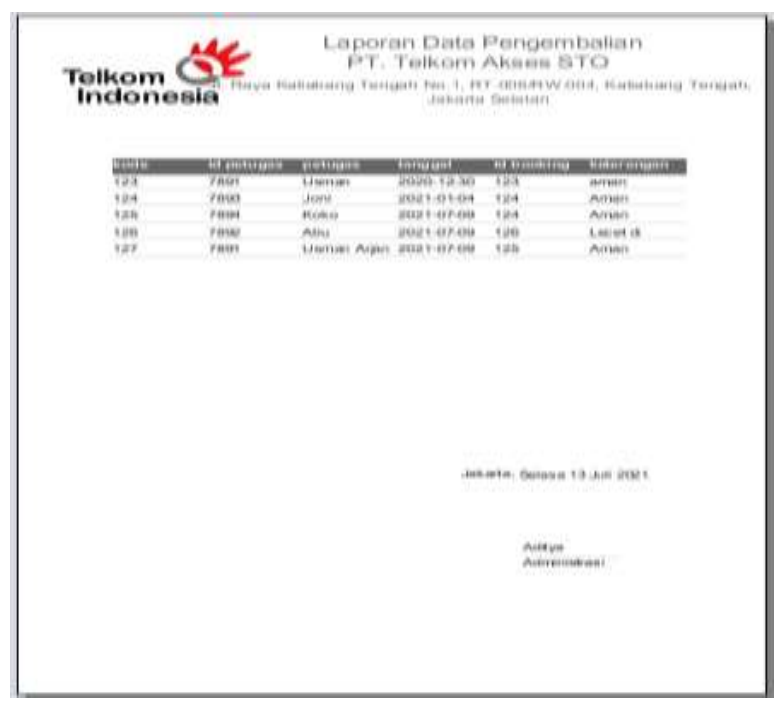

Gambar 10. Laporan Data Pengembalian Mobil

193 | Rancangan Aplikasi Peminjaman Kendaraan Operasional PT. Telkom Akses STO Kaliabang 
Layar di atas merupakan tampilan dari form laporan data pengembalian mobil. Pada layar form data pengembalian mobil digunakan dalam melakukan pengecekan laporan data pengembalian mobil yang terdiri dari Kode Pengembalian, ID Petugas, Nama Petugas, Tgl, ID Booking dan Keterangan.

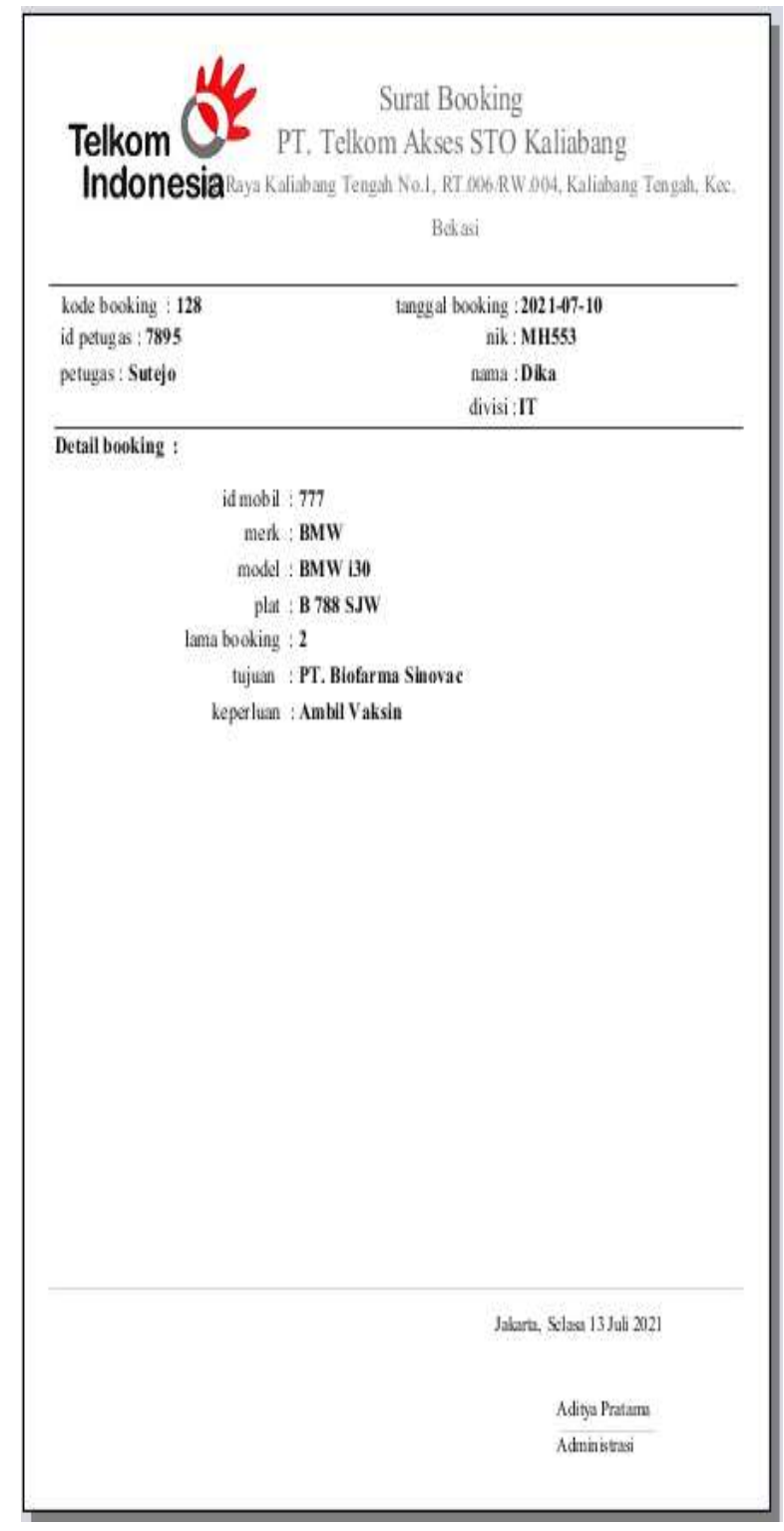

Gambar 11. Surat Booking Mobil

Layar di atas merupakan tampilan dari surat booking mobil. Pada bagian layar surat booking mobil terdapat Kode Booking, Tgl Booking, ID Petugas, Nama Petugas, NIK Karyawan , Nama Karyawan, Divisi, ID Mobil, Merk, Mobil, No Plat, Lama Booking, Tujuan dan Keperluan.

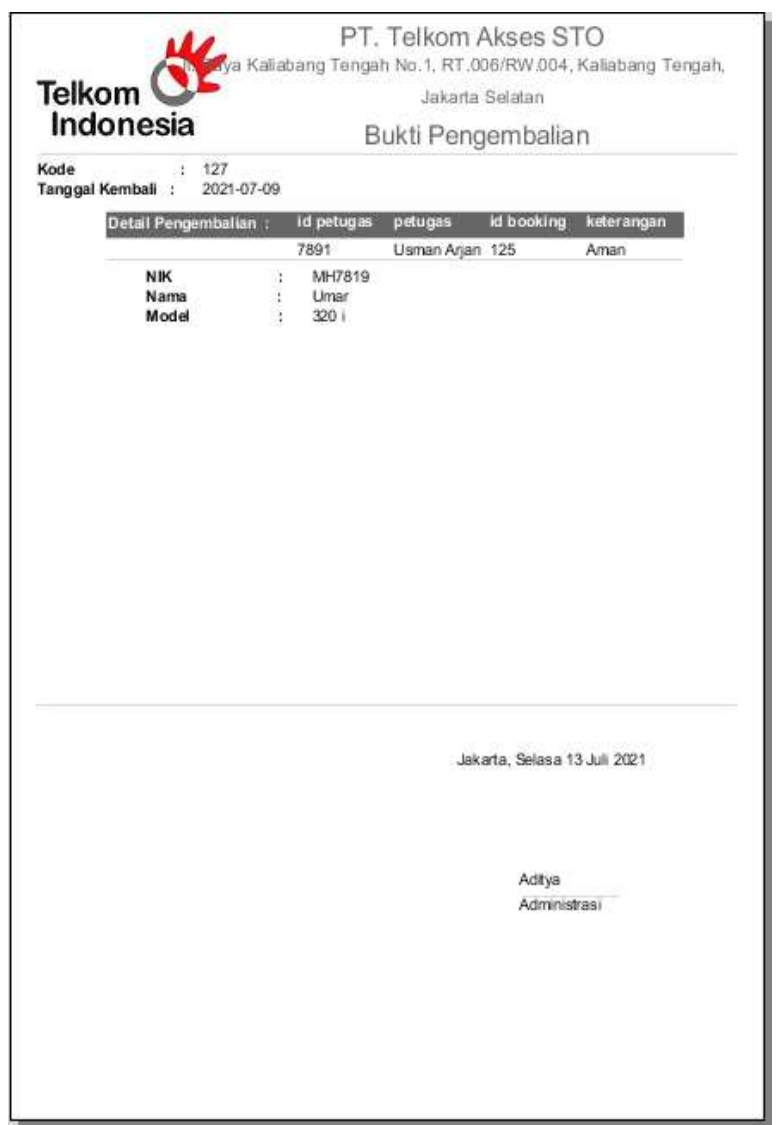

Gambar 12. Bukti Pengembalian Mobil

Layar di atas merupakan tampilan bukti pengembalian mobil. Pada tampilan layar bukti pengembalian mobil terdapat Kode Pengembalian, Tgl Kembali, ID Petugas, Nama Petugas, ID Booking, NIK, Nama Karyawan, Model dan Keterangan.

\section{SIMPULAN DAN SARAN}

PT. Telkom Akses STO Kaliabang sangat memerlukan suatu sistem yang terkomputerisasi, dengan aplikasi berbasis desktop ini dapat memudahkan admin dalam proses penginputan data serta memudahkan dalam pencarian data sehingga pelaporan menjadi lebih baik.

Saran yang dapat disampaikan adalah segala tindakan pengamanan perlu dilakukan karena komputer adalah alat yang sangat peka, maka keberadaannya harus dijaga dengan baik. Oleh sebab itu resiko kehilangan data dan rusaknya data harus diantisipasi dengan cara mem-backup data secara berkala. Perlu adanya pengawasan terhadap penerapan sistem yang diusulkan sehingga bila terdapat kelemahan bisa segera diperbaiki. 
DAFTAR PUSTAKA

Asra Mulya, Syarli, M. A. (2020). Peqguruang: Conference Series. JPCS, 2(1), 43-47.

Kurniawan, D. W., \& Irsyadi, F. Y. (2021). Perancangan dan Pembuatan Aplikasi Manajemen Peminjaman Kendaraan Berbasis Web Dengan Framework Codeigniter. 21(01).

Prasojo, M. (2011). Pengantar Sistem Informasi Manajemen . bandung: CV. Remadja Karya.

Pratama, R. S., Arifin, A. K., Citra, A., \& Dwi, D. (2020). Sistem Aplikasi Peminjaman Kendaraan Bermotor PT Trans Mitra Nusantara. $\quad 3(2), \quad 69-75$. https://doi.org/10.32493/jtsi.v3i2.3720

Satzinger, J. W., Jackson, R. B., Burd, S. D. (n.d.). System Analysis and Design in A Changing World. USA: Cengage Learning.

Shadiq, J., Safei, A., Wahyudin, R., \& Loly, R. (2021). Pengujian Aplikasi Peminjaman Kendaraan Operasional Kantor Menggunakan BlackBox Testing. 5(2), 97110.

Sugiyono. (2016). Metode Penelitian Kuantitatif, Kuantitadan $R \& D$. Bandung: PT Alfabet.

Sutabri, T. (2012). Analisis Sistem Informasi. Yogyakarta: Andi.

Trenggono, D. H. (2014). Perancangan Sistem Peminjaman Berbasis Web Sebagai Media Layanan di Studio Multimedia SMK 2 Sewon. Skripsi, 10-17.

Tyoso, J. S. P. (2016). Sistem Informasi Manajemen. Yogyakarta: DeePublish. 